\title{
Off-Pump Basilic-Cephalic Vein Coronary Artery Bypass Grafting: Desperate Times Call for Desperate Measures-A Case Report
}

\author{
Louis Samuels ${ }^{1 *}$, Alex Silverman ${ }^{2}$ and D Lynn Morris ${ }^{3}$ \\ ${ }^{1}$ Department of Surgery, Thomas Jefferson University, , USA \\ ${ }^{2}$ Undergraduate in Neuroscience, Vanderbilt University, USA \\ ${ }^{3}$ Department of Medicine, Albert Einstein Medical Center, USA
}

Submission: August 28, 2017; Published: August 30, 2017

*Corresponding author: JLouis Samuels, Department of Surgery, Division of Cardiothoracic Surgery, Thomas Jefferson University, Philadelphia, PA, USA, Email: samuelsle@aol.com

Abstract

We present a patient with symptomatic multi-vessel ischemic heart disease requiring surgical intervention. The saphenous veins and radial arteries were unsuitable conduits and the ascending aorta was near porcelain. Six off-pump coronary artery bypass (OP-CAB) were performed utilizing five grafts derived from the basilic-cephalic veins and one from the internal mammary artery. Coronary angiography one year later showed complete patency of all the grafts.

\section{Introduction}

The choice of conduits for coronary artery bypass grafting (CABG) includes arterial and venous options with the most common combination being the internal mammary artery (IMA) and greater saphenous vein (GSV). Additional bypass conduits include the radial artery (RA), gastroepiploic artery (GEA), and lesser saphenous vein [1]. On rare occasions, cadaver vein is used as a last resort biological conduit; even rarer is the role of the synthetic coronary bypass graft [2].

Similarly, the choice of how to conduct CABG surgery includes the traditional use of cardiopulmonary bypass (CPB) with aortic cross-clamping and cardioplegic arrest to beating heart with or without the aid of CPB (i.e. OP-CAB). In cases where choices are available, it is the surgeon's discretion and the knowledge gained from literature and experience that guide therapeutic and technical decision-making. However, in some cases, the menu of options is limited.

The purpose of this case report and literature review is to describe an unusual situation in which a patient with symptomatic ischemic heart disease required multiple coronary artery bypasses. The bypass conduit choices were limited and the aorta was unsuitable for safe CPB cannulation. An OP-CAB $\mathrm{X} 6$ with five grafts derived from basilic-cephalic veins and one from the internal mammary artery was performed successfully.
Coronary angiography a year later demonstrated complete patency of all the grafts.

\section{Case}

An 85 year-old man presented to the hospital with unstable angina. The past medical history was significant for hypertension; diabetes mellitus type II, chronic obstructive pulmonary disease, and congestive heart failure. Echocardiography and coronary angiographic findings demonstrated a moderately enlarged heart with an estimated left ventricular ejection fraction of $35 \%$, severe triple vessel coronary artery disease, moderate pulmonary hypertension (PAPs $50 \mathrm{mmHg}$ ), mild mitral regurgitation and moderate tricuspid insufficiency. He was deemed unsuitable for percutaneous coronary intervention. He was advised to undergo CABG surgery.

Further historical information and focused physical examination was significant for bilateral lower extremity severe varicosities in the greater and lesser saphenous systems. Allen's testing of the radial arteries proved negative making them unsafe for harvesting. Blood pressure measurements from both arms demonstrated lower values on the left side compared to the right suggestive of possible left subclavian artery stenosis. However, examination of the upper extremities showed an abundance of basilic and cephalic veins that appeared normal. 
The patient was brought to the operating room where basilic and cephalic vein harvesting was performed. The veins were suitable for use. Following sternotomy, the left internal mammary artery (LIMA) was harvested and prepared as a free graft because the inflow was suboptimal-presumably due to subclavian artery stenosis. A pericardial cradle was fashioned and cardiac inspection revealed a heavily plaque ridden ascending aorta. At this point, the decision was made to proceed without CPB using cardiac stabilizers in an OP-CAB approach.

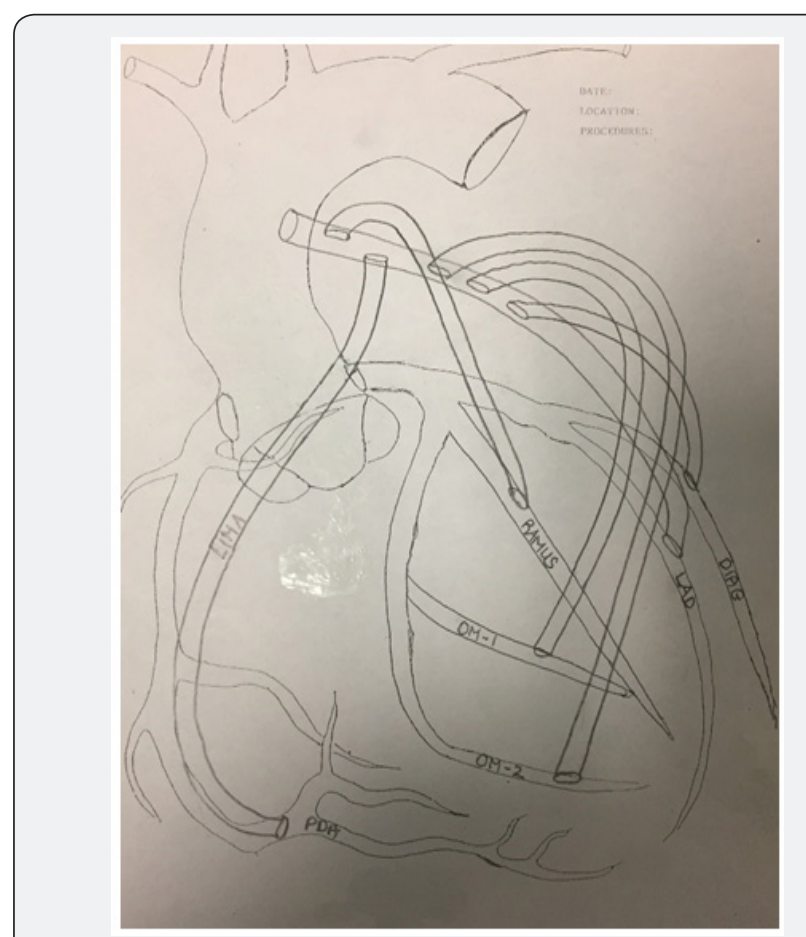

Figure 1: This graft was sewn to the left anterior descending (LAD) coronary artery and served as the origin for the other five grafts.

A single venous bypass conduit was anastamosed to the only plaque free area on the aorta using a specialized proximal anastamotic device (i.e. Heartstring ${ }^{\mathrm{TM}}$, Maquet Inc., Wayne, NJ, USA) to avoid clamping. This graft was sewn to the left anterior descending (LAD) coronary artery and served as the origin for the other five grafts (Figure 1). The free LIMA was anastamosed to the PDA while the remainder of the venous grafts was sewn to the diagonal branch, ramus intermedius, obtuse marginal-1, and obtuse marginal-2. The procedure was completed without adversity and the patient discharged with no major complications.

Initial follow-up showed left upper extremity swelling that responded to arm elevation and a compressive stocking appliance. Approximately a year postoperatively, the patient presented to the emergency room with vague chest pain. He was admitted for evaluation and investigation. Cardiac catheterization was performed and all grafts were patent (Figure 2). Medication adjustments were made and the patient discharged. He remained symptom-free as an outpatient for the next six years and ultimately expired seven years postoperatively following a fall with a head laceration at the age of 92 .

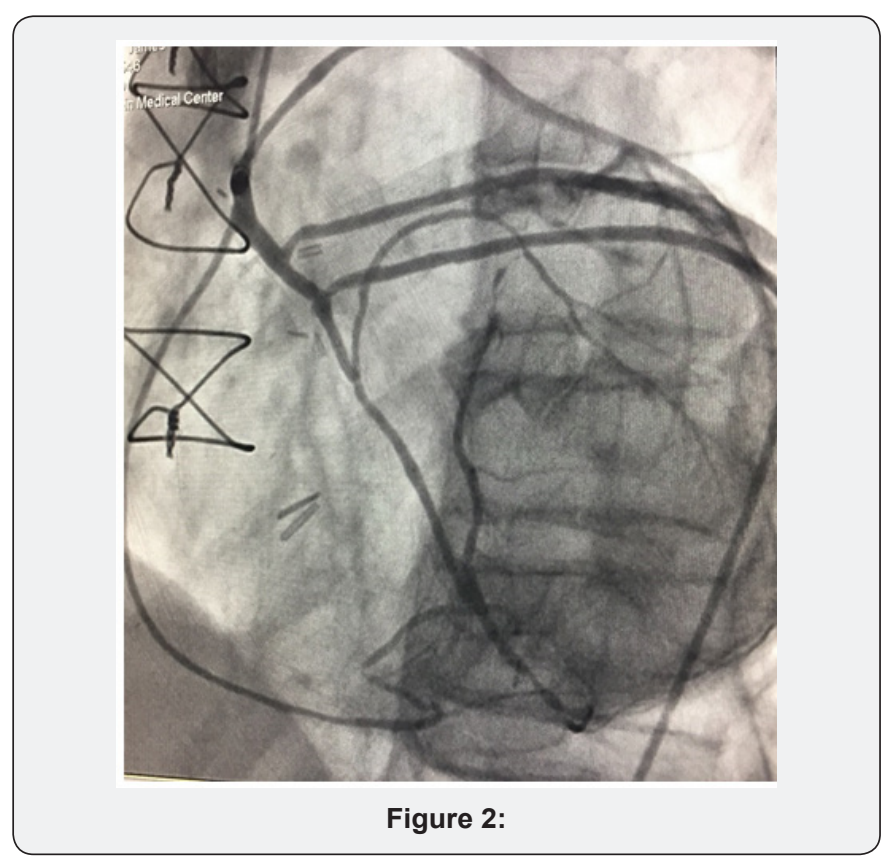

\section{Discussion}

The expression "Desperate time's call for desperate measures" is believed to have originated with a saying coined by Hippocrates in which he wrote "For extreme diseases, extreme methods of cure...are most suitable" [3].

The situation encountered in this case was challenging at multiple levels including the patient's advanced age, significant co-morbidities, cardiomyopathy, and limitations in therapeutic options for multi-vessel obstructive coronary arteriopathy. Although it is beyond the scope of this report to address the multitude of manuscripts on the characteristics of bypass graft conduits and choices in techniques for conducting CABG surgery, the underlying message is to act creatively and innovatively when confronted with unusual circumstances. The use of alternative conduit material and the ability to conduct beating heart coronary bypass surgery enables surgeons to "think outside the box".

The surgical literature is limited with respect to the use of basilic and cephalic veins for coronary revascularization. In 1984, Jarvinen et al. [4] reviewed their 1000 CABG operations in which 15 patients received arm vein grafts. Follow-up angiograms at a mean of 1.4 years postoperatively showed a patency rate of $87 \%$ for these arm vein grafts. Of interest was the frequent finding of uneven vein graft diameters and aneurysmal dilatation in three patients. In the same year (1984), Stoney et al. [5] published the fate of arm veins used for CABG in which 59 patients required at least one arm vein graft. Postoperative arteriogram in 28 patients showed $57 \%$ patency at two years with seven grafts showing localized areas of stenosis [5]. In 1996, Licht and colleagues reported the use of the cephalic vein 
for CABG in 39 patients over a 10-year period. Eighteen of the 39 were examined angiographically showing a $52 \%$ patency rate at a median follow-up of 31 months [6]. In 2007, Purohit \& Dunning [6] reported a literature review of cephalic vein graft patency in CABG surgery showing an approximate $50 \%$ three year patency. While the majority of these authors discourage the use of the cephalic vein for CABG surgery, it is within the context of other choices being available (e.g. internal mammary arteries, radial arteries, and saphenous veins). In one unique case described by the Bad Oeynhausen department of thoracic and cardiovascular surgery, the angiogram of a patent eighteen year old cephalic vein bypass to the right coronary artery was demonstrated [7].

Coronary artery bypass grafting remains the most commonly performed adult cardiac surgical procedure worldwide. And the most common conduits used for CABG cases are the internal mammary arteries (IMA) and saphenous veins (SVG). Although the experience with cephalic veins for CABG is limited and the data supports an inferior patency compared to the IMA and SVG, its use should not be forgotten in cases where typical bypass graft conduit availability is absent. The case presented here illustrates two important advances in complex surgical treatment of ischemic heart disease: 1) the use of the cephalic vein for CABG and 2) the use of an off-pump technique. Ironically, these two items represents an approach from the past and the state-of-theart. And perhaps Plato's words are best applied in this case and others: "Necessity is the mother of Invention" [8].

\section{References}

1. Buxton BF, Hayward PA, Newcomb AE, Moten S, Seevanayagam S, et al. (2009) Choice of conduits for coronary artery bypass grafting: craft or science? Eur J Cardiothorac Surg 35(4): 658-670.

2. Desai M, Seifalian AM, Hamilton G (2011) Role of prosthetic conduits in coronary artery bypass grafting. Eur J Cardiothorac Surg 40(2): 394398.

3. Aphorisms of Hippocrates, 400 BCE.

4. Järvinen A, Harjula A, Mattila S, Valle M, Harjola PT (1984) Experience with arm veins as aorto-coronary bypass grafts. J Cardiovasc Surg 25(4): 344-347.

5. Stoney WS, Alford WC, Burrus GR, Glassford DM, Petracek MR, et al. (1984) The fate of arm veins used for aorta-coronary bypass grafts. J Thorac Cardiovasc Surg 88(4): 522-526.

6. Purohit M, Dunning J (2007) Do coronary artery bypass grafts using cephalic veins have a satisfactory patency? Interact Cardiovasc Thorac Surg 6(2): 251-254.

7. Tjang YS, Hornik L, Seifert D, Körfer R (2008) Long-term patency of cephalic vein in coronary bypass surgery. J Card Surg 23(4): 366-384.

8. Plato's Republic, Book II, 369-c.

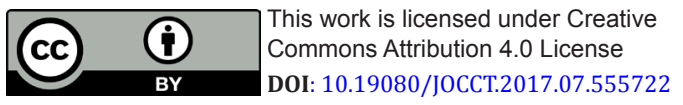

\begin{tabular}{l} 
Your next submission with Juniper Publishers \\
will reach you the below assets \\
- Quality Editorial service \\
- Swift Peer Review \\
- Reprints availability \\
- E-prints Service \\
- Manuscript Podcast for convenient understanding \\
- Global attainment for your research \\
- Manuscript accessibility in different formats \\
( Pdf, E-pub, Full Text, Audio) \\
- Unceasing customer service \\
Track the below URL for one-step submission \\
https://juniperpublishers.com/online-submission.php \\
\hline
\end{tabular}

